\title{
STRATEGI PENCEGAHAN PENCEMARAN LINGKUNGAN PELABUHAN PERIKANAN : KASUS PELABUHAN PERIKANAN NUSANTARA PALABUHANRATU
}

\author{
Strategy of Environmental Pollution Prevention in Fishing Port Case Study: Teritorial Fishing Port of \\ Palabuhanratu
}

Oleh:

\author{
Aris Wahyudi ${ }^{1 *}$, E. Lubis ${ }^{2}$, A.B. Pane ${ }^{2}$ \\ ${ }^{1}$ Mahasiswa Program Studi Teknologi Perikanan Laut \\ ${ }^{2}$ Staf Pengajar Program Studi Teknologi Perikanan Laut \\ Korespondensi: aries_wahyudi79@yahoo.co.id
}

\begin{abstract}
ABSTRAK
Pelabuhan Perikanan Nusantara Palabuhanratu (PPNPr) yang terletak di Teluk Palabuhanratu Kabupaten Sukabumi merupakan salah satu dari 15 Pelabuhan Perikanan Nusantara di Indonesia. Produksi perikanan tangkap di PPNPr tahun 2015 adalah $9.122 .320 \mathrm{~kg}$. Banyaknya produksi hasil tangkapan tanpa adanya pengelolaan yang baik pada aktivitas pendaratan, pengolahan, dan pemasaran, serta aktivitas lain akan berdampak buruk terhadap kondisi lingkungan PPNPr. Pencemaran lingkungan di PPNPr menjadi permasalahan penting yang harus dicari solusinya agar tercipta pelabuhan berwawasan lingkungan. Penelitian ini bertujuan untuk mengetahui pelaksanaan pencegahan pencemaran lingkungan di PPNPr dan menentukan strateginya. Metode penelitian ini adalah studi kasus terhadap strategi pencegahan pencemaran lingkungan pelabuhan perikanan kasus PPNPr. Data yang dikumpulkan adalah data primer dan sekunder yang selanjutnya dilakukan analisis deskriptif kualitatif, spasial dan Strength Weakness Opportunity Treath (SWOT). Hasil penelitian ini menyatakan bahwa pelaksanaan pencegahan pencemaran lingkungan di PPNPr telah melakukan kegiatan kebersihan, keamanan dan ketertiban (K3) yang belum optimal (belum dilengkapi peraturan, fasilitas, anggaran, pedoman praktis, sanksi dan sosialisasi). Strategi yang perlu dilakukan untuk pencegahan pencemaran lingkungan di PPNPr adalah peningkatkan kinerja pengelola dan pengguna pelabuhan dengan melaksanakan program kerja bersama, penerapan peraturan dengan sanksi yang tegas, dan pengawasan ketat, serta meningkatkan sosialisasi kepada pengguna terhadap kebersihan lingkungan pelabuhan.
\end{abstract}

Keywords : pelabuhan perikanan, pencemaran, palabuhanratu, SWOT.

\begin{abstract}
Teritorial Fishing Port of Palabuhanratu (TFPPr) located in Palabuhanratu Bay, Sukabumi Regency is one of 15 Teritorial Fishing Ports in Indonesia. In 2015, production of capture fisheries in TFPPr amounted to 9,122,320 kg. A large number of fish available without proper management of landing, processing and marketing activities, as well as other activities will adversely affect the environmental conditions of TFPPr. Environmental pollution in TFPPr becomes an important issue that should be solved in order to create a fishing port. This study was aimed to determine the implementation of environmental pollution prevention in TFPPr and determine the relevant strategy. Research method applied was a case study on environmental pollution prevention strategy in fishing port of TFPP case. The data collected were primary and secondary data of which analysis of qualitative descriptive, spatial and Strength Weakness Opportunity Threat (SWOT) was further conducted based on the data. The results of this study indicate that the implementation of environmental pollution
\end{abstract}


prevention in TFPPr has conducted cleanliness, securities and orderliness (K3) activities that was not yet optimal (not yet equipped with regulations, facilities, budget, practical guidance, sanction and socialization). The strategy that needs to be done for the prevention of environmental pollution in TFPPr was improving the performance of port managers and users by implementing joint work program, the implementation of the regulation with strict sanction, strict supervision, and increasing the socialization to the users on the cleanliness of port environment.

Keywords: fishing port, palabuhanratu, pollution, SWOT.

\section{PENDAHULUAN}

Pelabuhan perikanan adalah suatu perpaduan antara wilayah daratan dan lautan yang digunakan sebagai pangkalan kegiatan penangkapan ikan dan dilengkapi dengan berbagai fasilitas sejak ikan didaratkan sampai ikan didistribusikan (Lubis 2012). Selanjutnya Lubis mengatakan bahwa fungsi dari pelabuhan perikanan adalah mendukung semua kegiatan yang berhubungan dengan pemanfaatan sumberdaya ikan dan lingkungan.

Menghadapi globalisasi dan perdagangan bebas di kalangan MEA sudah menjadi prasyarat mutlak untuk memperhatikan kondisi lingkungan di kawasan pesisir dan pelabuhan agar terjaga kebersihannya dengan baik. Peraturan ini bertujuan untuk menjamin kebersihan lingkungan baik pada proses produksi, pemasaran, pengola-han, maupun distribusi ikan. Undang-Undang Nomor 32 Tahun 2009 tentang Perlindungan dan Pengelolaan Ling-kungan Hidup menyatakan bahwa pencegahan pencemaran merupakan suatu kegiatan dengan mengupayakan secara dini, terencana, terpadu, dan terukur agar aktivitas-aktivitas para penguna pelabuhan perikanan di kawasan pelabuhan perikanan tidak menyebabkan terjadinya pencemaran lingkungan.

Kondisi terkini pelabuhan perikanan di Indonesia secara umum masih mengalami banyak permasalahan terutama terkait sanitasi dan higienitas yang masih buruk. Lubis (2012) menyatakan bahwa secara umum kondisi pelabuhan perikanan di Indonesia selama ini masih dipandang kurang baik karena kekotoran dan kekumuhan masih terlihat di area sekitar pelabuhan. Pelabuhan Perikanan Nusantara Palabuhanratu (PPNPr) merupakan salah satu dari 15 Pelabuhan Perikanan Nusantara di Indonesia dan satu-satunya pelabuhan perikanan dengan hasil produksi perikanan tangkap terbesar di Provinsi Jawa Barat. Pelabuhan ini terletak di Teluk Palabuhanratu Kabupaten Sukabumi yang masuk diwilayah Samudra Hindia (WPPRI 573). Produksi perikanan tangkap di PPNPr sangat potensial, hal ini didukung dengan hasil produksi sebesar $9.122 .320 \mathrm{~kg}$ pada tahun 2015 (PPN Palabuhanratu 2015). Aktivitas pendaratan, pengolahan, dan pemasaran ikan di PPNPr dalam pengelolaannya belum memperhatikan kondisi lingkungan. Sehingga terlihat pelabuhan perikanan kotor dan kumuh yang diindikasikan dengan adanya limbah berupa potongan-potongan tubuh ikan, air bekas pencucian ikan, darah ikan, dan ceceran solar pada saat pengisian bahan bakar. Pane (2008) menyatakan bahwa keberadaan ceceran potongan bagian ikan, ikan utuh yang rusak, genangan cairan dan lendir; baik di dermaga pendaratan dan tempat pelelangan ikan menjadi pertanda bahwa sanitasi dan higienitas di lingkungan pelabuhan masih rendah.

Pencemaran lingkungan di PPNPr menjadi salah satu permasalahan penting yang harus dicari solusinya agar tercipta pelabuhan berwawasan lingkungan. Sehingga perlu dilakukan penelitian tentang strategi pencegahan pencemaran lingkungan pelabuhan perikanan kasus PPNPr. Penelitian sebelumnya terkait lingkungan pelabuhan perikanan telah dilakukan oleh Risnandar (2013) dengan hasil bahwa fasilitas pengelolaan lingkungan di PPNPr belum sesuai dengan yang seharusnya sebagaimana disampaikan dalam Peraturan Menteri Negara Lingkungan Hidup Nomor 05 tahun 2009 tentang Pengelolaan Limbah di Pelabuhan. Pelabuhan Perikanan Samudera Nizam Zachman Jakarta dalam operasionalnya juga kurang memperhatikan aspek ekologi lebih pada aspek sosial dan ekonomi 
(Suprianto 2013). Penelitian ini bertujuan untuk mengetahui seberapa jauh pelaksanaan pencegahan pencemaran lingkungan di PPNPr dan menentukan strateginya.

\section{METODE PENELITIAN}

Penelitian dilaksanakan Juli - Agustus 2016 di PPNPr Kabupaten Sukabumi, Provinsi Jawa Barat dengan metode studi kasus terhadap permasalahan buruknya sanitasi dan higienitas di lingkungan pelabuhan perikanan PPNPr. Aspek yang dikaji adalah pencegahan pencemaran lingkungan. Aspek ini akan dikaitkan dengan faktor-faktor untuk membuat strategi yang meliputi: keberadaan aturan, unit kerja, program kerja, sarana dan prasarana, anggaran dana, pelaksanaan program kerja, pedoman praktis pengguna pelabuhan, partisipasi aktif pengguna pelabuhan (nelayan, pedagang, pengolah ikan, pihak perusahaan, pihak pelelangan ikan, pedagang ikan, dan pengunjung pelabuhan) hasil kegiatan, reward, sanksi, audit internal, pengarahan hierarki atas, audit eksternal, dan keberadaan Sungai Cipalabuhanratu.

Pengumpulan data dan informasi meliputi data sekunder, data primer (wawancara dan pengamatan di lokasi penelitian). Wawancara dilakukan dengan menggunakan kuesioner mengenai pencegahan pencemaran lingkungan di PPNPr. Penentuan responden adalah purposive sampling. Responden yang dipilih berjumlah 26 orang terdiri dari; 3 pengelola pelabuhan, 3 pihak perusahaan, 3 nelayan gillnet, 3 nelayan bagan, 5 nelayan pancing ulur, 4 nelayan payang dan 5 pedagang ikan.

Data dianalisis secara deskriptif kualitatif setelah dilakukan pengamatan terhadap aktivitas, fasilitas pendukung lingkungan yang berpotensi menimbulkan pencemaran lingkungan dan dilakukan analisis spasial untuk penyebaran pencemaran, serta Analisis SWOT sesuai dengan panduan oleh Rangkuti (2016). Setiap parameter SWOT dianalisis secara deskriptif kualitatif setelah dilakukan scoring method, terhadap jawaban atas pertanyaan/parameter yang diajukan kepada responden (pengelola PPNPr, pihak perusahaan, nelayan, dan pedagang) yang mengetahui benar mengenai faktorfaktor pencegahan pencemaran lingkungan di PPNPr seperti yang telah dilakukan oleh Pane (2016).

Tahapan Analisis SWOT meliputi :

1. Perhitungan faktor-faktor internal dan eksternal pencegahan pencemar an lingkungan di PPNPr menggunakan data kualitatif yang dikuantitatifkan dengan cara :

a. Membuat pertanyaan-pertanyaan faktor internal dan eksternal pencegahan pencemaran lingkungan di PPNPr (Tabel 1).

b. Membuat kriteria untuk pengambilan keputusan (termasuk didalamnya pembobotan pada Tabel 2) :

b1. Perhitungan jumlah nilai maksimum (JNMax) skor responden (Tabel 3).

b2. Penentuan kriteria pengambilan keputusan (Tabel 4).

c. Pengolahan data jawaban responden; diperoleh jumlah nilai (JN) (Tabel 5).

d. Pengambilan keputusan.

Tabel 1 Pertanyaan-pertanyaan faktor internal dan eksternal, pilihan jawaban dan skor SWOT

\begin{tabular}{cccc}
\hline No & $\begin{array}{c}\text { Pertanyaan-pertanyaan faktor internal dan eksternal, pilihan } \\
\text { jawaban dan skor }\end{array}$ & $\begin{array}{c}\text { Pilihan jawaban } \\
\text { responden }\end{array}$ & Skor \\
\hline \multirow{2}{*}{1} & Pertanyaan 1 : Ada tidaknya parameter internal SWOT ? & Ada & 2 \\
& & Tidak Ada & 1 \\
2 & Pertanyaan 2 : Ada tidaknya parameter eksternal SWOT ? & Ada & 2 \\
3 & Didak Ada & 1 \\
\hline
\end{tabular}


Tabel 2 Pembobotan faktor internal dan eksternal komponen SWOT

\begin{tabular}{cccccccc}
\hline No & $\begin{array}{c}\text { Faktor internal: } \\
\text { Variabel H }><\text { Variabel V }\end{array}$ & V1 & V2 & V3 & V4 & $\begin{array}{c}\text { Jumlah } \\
\text { Horizontal }\end{array}$ & n2 \\
\hline H1 & Keberadaan pertanyaan 1 & & & & & $\ldots$ & $\ldots$ \\
H2 & Keberadaan pertanyaan 2 & $\ldots$ & & & & $\ldots$ & $\ldots$ \\
H3 & Keberadaan pertanyaan 3 & $\ldots$ & $\ldots$ & & & $\ldots$ & $\ldots$ \\
H4 & Keberadaanpertanyaan dst & $\ldots$ & $\ldots$ & $\ldots$ & & $\ldots$ & $\ldots$ \\
& Jumlah Vertikal & $\ldots$ & $\ldots$ & $\ldots$ & $\ldots$ & $\square$ & $\square$ \\
& n1 & $\ldots$ & $\ldots$ & $\ldots$ & $\ldots$ & $\square$ & $\square$ \\
& Jumlah Horizontal & $\ldots$ & $\ldots$ & $\ldots$ & $\ldots$ & $\square$ & $\square$ \\
n2 & $\ldots$ & $\ldots$ & $\ldots$ & & $\square$ & $\square$ \\
& Bobot & $\ldots$ & $\ldots$ & $\ldots$ & $\ldots$ & $\square$ & $\square$ \\
\hline
\end{tabular}

Keterangan :

Derajat kepentingan perbandingan Variabel $\mathrm{H}$ terhadap Var V:

$$
\begin{aligned}
& 3=\text { Variabel H lebih penting daripada Variabel V } \\
& 2=\text { Variabel H sama penting daripada Variabel V } \\
& 1=\text { Variabel H kurang penting daripada Variabel V }
\end{aligned}
$$

$\begin{array}{lll}\text { Bobot } 1 & \text { : Bobot data kualitatif } & \mathrm{H}: \text { Horizontal } \\ \text { Jumlah }(\mathrm{V}) & \text { : Jumlah kolom vertikal } & \mathrm{V}: \text { Vertikal } \\ \text { Jumlah }(\mathrm{H}) & \text { : Jumlah kolom horizontal } & \\ \mathrm{n} 1 & \text { : Banyak variabel baris digunakan pada setiap kolom } & \\ \mathrm{n} 2 & \text { : Banyak variabel kolom digunakan pada setiap baris } & \end{array}$

Tabel 3 Perhitungan jumlah nilai maksimum (JN Max) skor responden

\begin{tabular}{cccccc}
\hline No & $\begin{array}{c}\text { Faktor Internal dan eksternal } \\
\text { SWOT }\end{array}$ & Skor Max & Bobot & $\begin{array}{c}\text { Jumlah } \\
\text { Responden }\end{array}$ & $\begin{array}{c}\text { Jumlah Nilai } \\
\text { Terhitung Max } \\
(N \text { max })\end{array}$ \\
\hline 1 & Keberadaan pertanyaan 1 & $\mathrm{a}=1,2, \ldots \mathrm{dst}$ & $\mathrm{b}$ & $\mathrm{c}=1,2, \ldots \mathrm{dst}$ & $\mathrm{d}=\mathrm{a}+\mathrm{b}+\mathrm{c}$ \\
2 & Keberadaan pertanyaan 2 & $\mathrm{a}=1,2, \ldots \mathrm{dst}$ & $\mathrm{b}$ & & $\mathrm{d}=\mathrm{a}+\mathrm{b}+\mathrm{c}$ \\
3 & Keberadaan pertanyaan 3 & $\mathrm{a}=1,2, \ldots \mathrm{dst}$ & $\mathrm{b}$ & $\mathrm{d}=\mathrm{a}+\mathrm{b}+\mathrm{c}$ \\
4 & Keberadaan pertanyaan dst & $\mathrm{a}=1,2, \ldots \mathrm{dst}$ & $\mathrm{b}$ & $\mathrm{d}=\mathrm{a}+\mathrm{b}+\mathrm{c}$ \\
\hline \multicolumn{7}{c}{ Subjumlah } & $\sum a$ & $\sum b$ \\
\hline
\end{tabular}

Keterangan :
a : Skor maksimal per variabel
b : Skor bobot maksimal per variabel
c : Skor jumlah responden maksimal per variabel
Ia : Jumlah skor maksimal semua variabel
$\mathrm{d}$ atau $\mathrm{N} \max \quad$ : Jumlah nilai maksimum jawaban responden per variabel
$\sum d$ atau JN max : Jumlah nilai maksimum jawaban semua responden 
Tabel 4 Penentuan kriteria pengambilan keputusan

\begin{tabular}{ccc}
\hline Jumlah Nilai Jawaban Responden JN terhadap Nmax & Keputusan \\
\hline Selang Kelas JN (\%) & Nilai Selang Kelas JN & \\
$\mathrm{JN}<40 \%$ & $\mathrm{JN}<\mathrm{a}$ & Sangat kurang \\
$40 \%<=\mathrm{JN}<55 \%$ & $\mathrm{a}<\mathrm{JN}>\mathrm{b}$ & Kurang \\
$55 \%<=\mathrm{JN}<70 \%$ & $\mathrm{~b}<\mathrm{JN}>\mathrm{c}$ & Cukup/sedang \\
$70 \%<=\mathrm{JN}<85 \%$ & $\mathrm{c}<\mathrm{JN}>\mathrm{d}$ & Baik \\
$\mathrm{JN}>=85$ & $\mathrm{JN}>\mathrm{d}$ & Sangat Baik \\
\hline
\end{tabular}

Keterangan :

a : Nilai selang kelas $\quad \mathrm{c}:$ Nilai selang kelas

$\mathrm{b}$ : Nilai selang kelas $\quad \mathrm{d}$ : Nilai selang kelas

Tabel 5 Pengolahan data jawaban responden dari faktor-faktor internal dan eksternal SWOT

\begin{tabular}{|c|c|c|c|c|c|}
\hline No & $\begin{array}{c}\text { Faktor Internal } \\
\text { dan eksternal } \\
\text { SWOT }\end{array}$ & Skor & Bobot & $\begin{array}{c}\text { Jumlah } \\
\text { Responden }\end{array}$ & $\begin{array}{c}\text { Jumlah Nilai } \\
\text { Terhitung } \\
\text { Responden } \\
(J N)\end{array}$ \\
\hline 1 & $\begin{array}{c}\text { Keberadaan } \\
\text { pertanyaan } 1\end{array}$ & $\mathrm{a}=1,2, \ldots \mathrm{dst}$ & $\mathrm{b}$ & $\mathrm{c}=1,2, \ldots \mathrm{dst}$ & $\mathrm{d}=\mathrm{a}+\mathrm{b}+\mathrm{c}$ \\
\hline 2 & $\begin{array}{c}\text { Keberadaan } \\
\text { pertanyaan } 2\end{array}$ & $\mathrm{a}=1,2, \ldots \mathrm{dst}$ & $\mathrm{b}$ & & $d=a+b+c$ \\
\hline 3 & $\begin{array}{c}\text { Keberadaan } \\
\text { pertanyaan } 3\end{array}$ & $\mathrm{a}=1,2, \ldots \mathrm{dst}$ & $\mathrm{b}$ & & $\mathrm{d}=\mathrm{a}+\mathrm{b}+\mathrm{c}$ \\
\hline 4 & $\begin{array}{c}\text { Keberadaan } \\
\text { pertanyaan dst }\end{array}$ & $\mathrm{a}=1,2, \ldots \mathrm{dst}$ & $\mathrm{b}$ & & $\mathrm{d}=\mathrm{a}+\mathrm{b}+\mathrm{c}$ \\
\hline & Subjumlah & $\sum a$ & & & $\sum d$ \\
\hline
\end{tabular}

Keterangan :
a : Skor per variabel
b : Skor bobot per variabel
c : : Skor jumlah responden per variabel
Sa : Jumlah skor maksimal semua variabel
$\mathrm{d}$ atau JN $\quad$ : Jumlah nilai jawaban responden per variabel
$\sum d$ atau JN max : Jumlah nilai jawaban semua responden

Setelah melalui proses pada tabel diatas, langkah berikutnya adalah pengambilan keputusan untuk masing-masing komponen SWOT dengan cara; membandingkan komponen JN kekuatan $><\mathrm{JN}$ max kekuatan, JN kelemahan $><$ JNmax kelemahan, JN peluang $><$ JNmax peluang, JN ancaman $><$ JNmax ancaman, dan JN internal $><$ JNmax internal, JN eksternal $><$ JNmax eksternal, serta JN 4 internal dan eksternal $><$ JNmax internal dan eksternal (Tabel 6 dan 7). 
Tabel 6 Nilai JN untuk 4 faktor internal dan eksternal SWOT dan jumlahnya

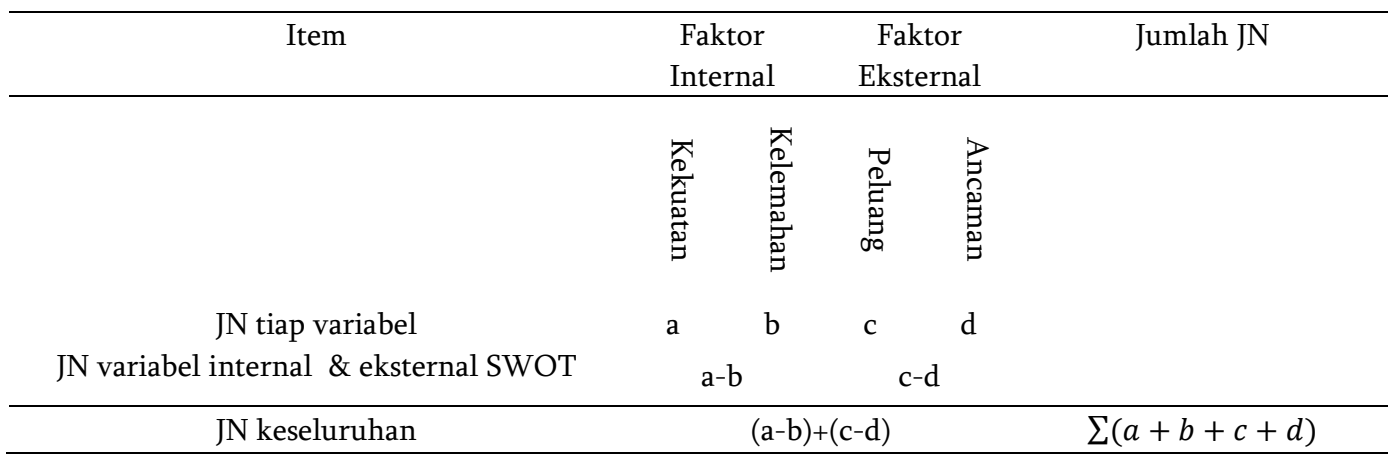

Tabel 7 Nilai JNMax untuk 4 faktor internal dan eksternal SWOT dan jumlahnya

\begin{tabular}{|c|c|c|c|c|c|}
\hline \multirow[t]{2}{*}{ Item } & \multicolumn{2}{|c|}{$\begin{array}{c}\text { Faktor } \\
\text { Internal }\end{array}$} & \multicolumn{2}{|c|}{$\begin{array}{c}\text { Faktor } \\
\text { Eksternal }\end{array}$} & \multirow[t]{2}{*}{ Jumlah JNMax } \\
\hline & 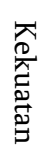 & 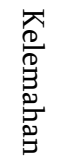 & 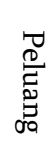 & 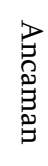 & \\
\hline JN Max tiap variabel & $\mathrm{a}$ & $\mathrm{b}$ & c & $\mathrm{d}$ & \\
\hline $\begin{array}{l}\text { JN Max variabel internal \& eksternal } \\
\text { SWOT }\end{array}$ & \multicolumn{2}{|c|}{$\mathrm{a}-\mathrm{b}$} & \multicolumn{2}{|c|}{$c-d$} & \\
\hline JN Max keseluruhan & \multicolumn{4}{|c|}{$(a-b)+(c-d)$} & $\sum(a+b+c+d)$ \\
\hline
\end{tabular}

\section{HASIL DAN PEMBAHASAN}

\section{Pelaksanaan Pencegahan Pencemaran Lingkungan di Pelabuhan Perikanan Nusantara Palabuhanratu}

Berbagai aktivitas di PPNPr dalam pelaksanaannya belum memperhatikan kondisi lingkungan. Keberadaan limbah padat (sampah plastik, ceceran ikan, dan puntung rokok) dan cair (ceceran darah ikan, solar dan sisa es) menjadi indikator bahwa PPNPr kondisi lingkungannya masih kurang baik terutama di area kolam pelabuhan (Gambar 1). Chen dan Liu (2013) menyatakan jenis limbah yang dibuang dari aktivitas kapal yang berlabuh di dermaga pada umumnya berupa sampah botol plastik, kantong plastik, dan alat tangkap (tali pancing, jaring dan tali pelampung). Hal ini juga terjadi pada lingkungan di PPNPr (Tabel 8).

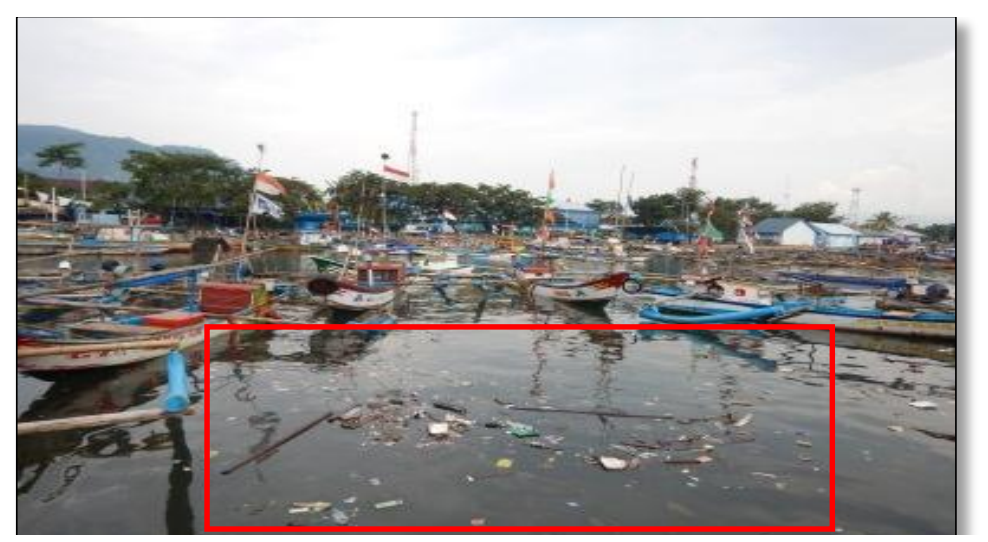

Gambar 1 Keberadaan limbah di kolam pelabuhan di PPNPr tahun 2016 
Tabel 8 Aktivitas, fasilitas pendukung lingkungan dan bentuk pencemaran lingkungan di PPNPr

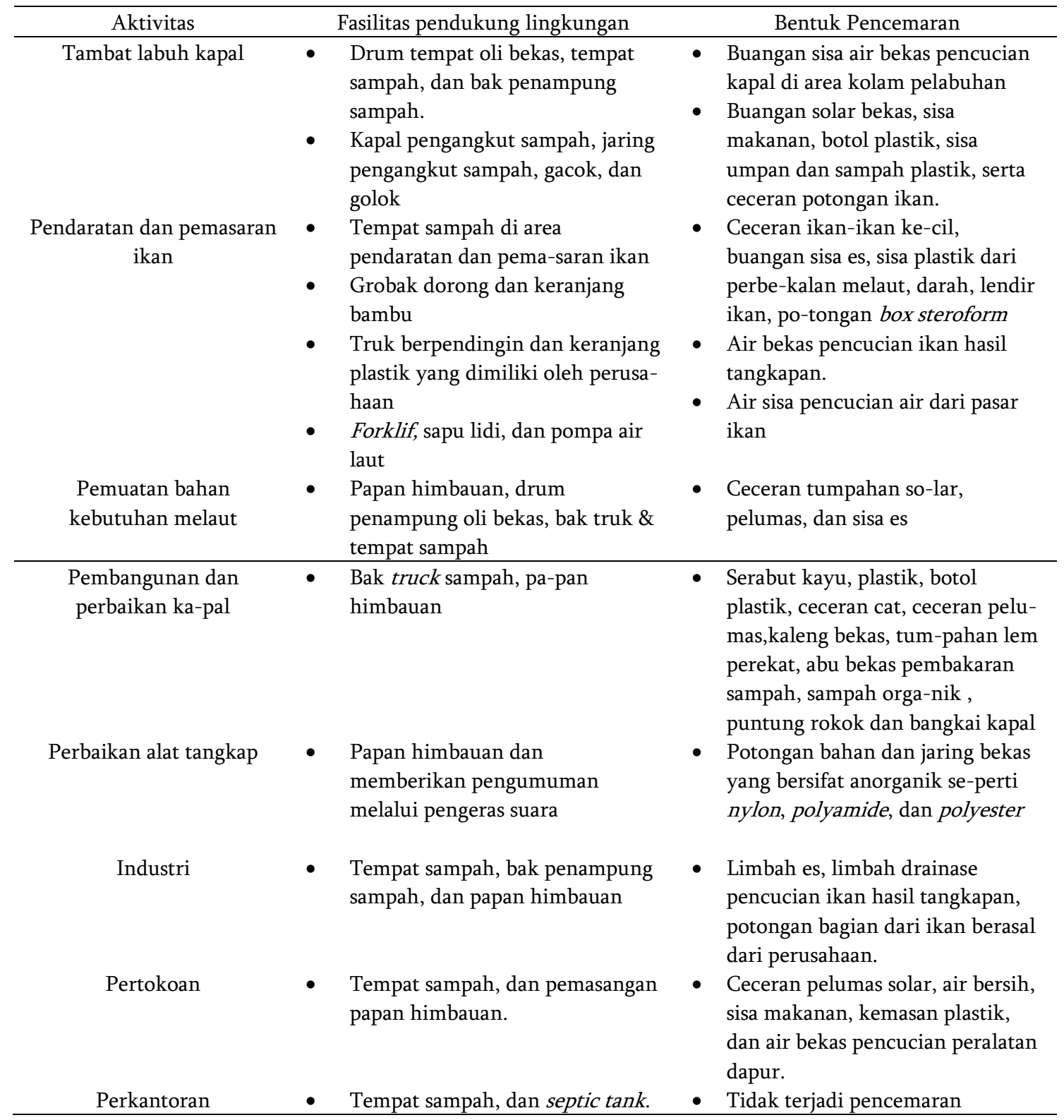

Sumber : PPN Palabuhanratu 2016 (data diolah kembali)

Bersadarkan tabel diatas diketahui bahwa sebagian besar sampah yang dihasilkan dari aktivitas di lingkungan PPNPr berupa sampah jenis anorganik. Masalah pencemaran lingkungan di pelabuhan dapat terjadi karena keterbatasan fasilitas kebersihan, sedikitnya peraturan dan rendahnya kesadaran dan kepedulian pengguna pelabuhan terhadap kebersihan lingkungan PPNPr. Jailan et al. (2016) menyatakan bahwa semakin padat penduduk di suatu wilayah, maka semakin komplek permasalahan akibat sampah. Fakta di lapangan menunjukkan hal yang sama yaitu masyarakat pelabuhan tidak lagi peduli lingkungannya atau memiliki kesadaran yang rendah untuk membuang sampah pada tempat yang telah dianjurkan.

Aktivitas yang berhubungan dengan kegiatan aktivitas kapal seperti tambat labuh kapal, pendaratan dan pemasaran ikan hasil tangkapan, pemuatan kebutuhan melaut, pembangunan dan 
perbaikan kapal, serta perbaikan alat tangkap berpotensi besar menjadi sumber terjadinya pencemaran lingkungan. Dampak negatif keberadaan aktivitas tambat labuh kapal, pendaratan dan pemasaran ikan, serta aktivitas-aktivitas lain di lingkungan pelabuhan berupa keberadaan limbah padat dan cair menjadi penyebab terjadinya pencemaran lingkungan (Wirdah 2006). Selanjutnya Sidabur (2008) menyatakan bahwa salah satu sumber pencemaran di lingkungan pesisir dan pelabuhan adalah berasal dari kegiatan aktivitas kapal yang ada di pelabuhan. Culin dan Bielic (2016) juga menyatakan bahwa limbah dominan yang dihasilkan dari kapal berupa plastik, ceceran oli bekas dan limbah cair.

Aktivitas di Tempat Pelelangan Ikan (TPI), dermaga dan pengolahan ikan menghasilkan limbah berupa ceceran ikan-ikan kecil, sisa plastik, air sisa pencucian ikan, dan lendir yang berasal dari darah ikan. Sari (2003) menyatakan bahwa kegiatan di TPI menimbulkan limbah ikan berupa sisik, kepala, ekor dan isi perut ikan. Penyajian peta penyebaran pencemaran menurut jenis cemaran dominan di lokasi kegiatan dapat disajikan pada (Gambar 2).
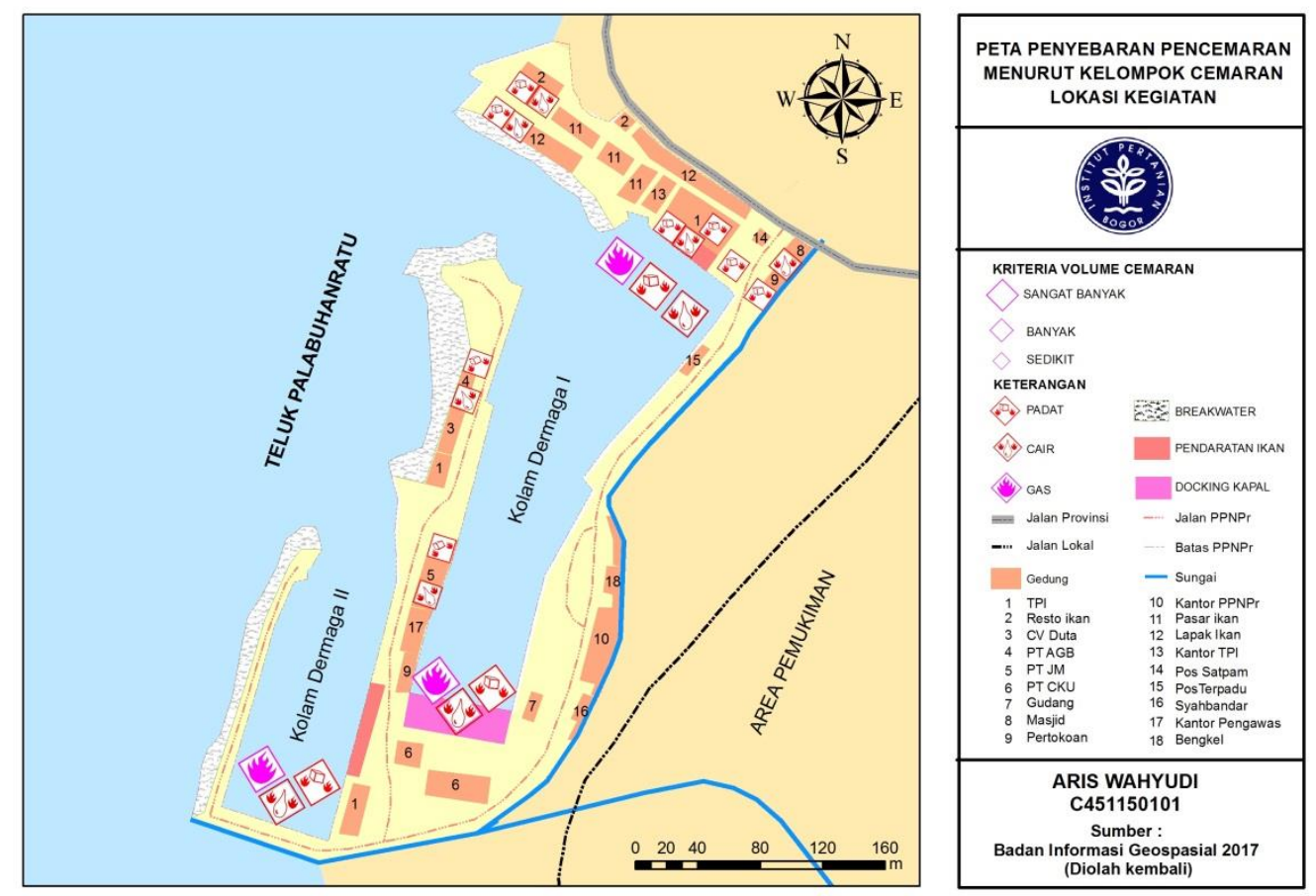

Gambar 2 Peta penyebaran pencemaran menurut jenis cemaran dominan lokasi kegiatan

Penentuan strategi pencegahan pencemaran lingkungan di PPNPr diperolah dari faktor-faktor internal dan eksternal yang disajikan pada Matrik IFAS (Tabel 9) dan EFAS (Tabel 10).

Tabel 9 Matrik IFAS strategi pencegahan pencemaran lingkungan di PPNPr tahun 2006

\begin{tabular}{|c|c|c|c|c|}
\hline Pertanyaan faktor-faktor internal & Bobot & Skor & $\begin{array}{l}\text { Jumlah } \\
\text { responden }\end{array}$ & $\begin{array}{c}\text { Jumlah } \\
\text { Nilai }\end{array}$ \\
\hline \multicolumn{5}{|l|}{ Kekuatan (Strength) } \\
\hline $\begin{array}{l}\text { 1. Adanya unit kerja pencegahan pencemaran } \\
\text { lingkungan di PPNPr }\end{array}$ & 2.0 & 2 & 26 & 104.0 \\
\hline $\begin{array}{l}\text { 2. Adanya program kerja pencegahan pencemaran } \\
\text { lingkungan }\end{array}$ & 2.0 & 2 & 26 & 104.0 \\
\hline $\begin{array}{l}\text { 3. Adanya pelaksanaan program kerja pencegahan } \\
\text { pencemaran lingkungan di PPNPr }\end{array}$ & 2.0 & 2 & 26 & 104.0 \\
\hline
\end{tabular}




\begin{tabular}{|c|c|c|c|c|c|}
\hline & $\begin{array}{l}\text { Adanya audit internal dalam pelaksanaan } \\
\text { pencegahan pencemaran lingkungan di PPNPr }\end{array}$ & 2.3 & 2 & 26 & 121.3 \\
\hline & $\begin{array}{l}\text { Jumlah Nilai } \\
\end{array}$ & 8.3 & & & 433.3 \\
\hline \multicolumn{6}{|c|}{ Kelemahan (Weakness) } \\
\hline 1 . & $\begin{array}{l}\text { Tidak ditaati aturan yang dibuat oleh pengelola } \\
\text { PP kepada para pengguna pelabuhan }\end{array}$ & 2.6 & 1 & 25 & 65.0 \\
\hline 2 . & $\begin{array}{l}\text { Keterbatasan sarana dan prasarana pelaksanaan } \\
\text { pencegahan pencemaran di PPNPr }\end{array}$ & 2.2 & 1 & 26 & 57.2 \\
\hline 3. & $\begin{array}{l}\text { Keberadaan anggaran yang belum cukup } \\
\text { dalam pelaksanaan pencegahan pencemaran di } \\
\text { PPNPr }\end{array}$ & 1.4 & 1 & 16 & 22.4 \\
\hline 4 . & $\begin{array}{l}\text { Masih sedikitnya pedoman praktis bagi para } \\
\text { pengguna pelabuhan perikanan }\end{array}$ & 2.0 & 1 & 25 & 50.0 \\
\hline 5. & $\begin{array}{l}\text { Masih sedikitnya hasil dari kegiatan } \\
\text { pencegahan pencemaran }\end{array}$ & 1.8 & 2 & 20 & 72.0 \\
\hline \multirow[t]{2}{*}{6.} & $\begin{array}{l}\text { Sedikitnya pengawasan dan tidak adanya } \\
\text { pemberian sanksi bagi penguna pelabuhan } \\
\text { yang membuang sampah sembarangan }\end{array}$ & 1.2 & 1 & 26 & 24.0 \\
\hline & Jumlah Nilai (JN) & 11.2 & & & 290.6 \\
\hline
\end{tabular}

Sumber : PPN Palabuhanratu 2016 (data diolah kembali)

Hasil perhitungan faktor kekuatan pencegahan pencemaran di PPNPr pada Tabel 9, memberikan nilai sebesar 433.3 yang termasuk dalam nilai selang pengambilan keputusan faktor kekuatan $\mathrm{JN}>85 \%(\mathrm{JN}>368.3)$ yang berarti sisi faktor kekuatan adalah sangat baik. Pada faktor kelemahan menghasilkan nilai sebesar 290.6 yang termasuk dalam nilai pengambilan keputusan faktor kelemahan $40 \%<\mathrm{JN}>55 \%$ yang berarti sisi faktor kelemahan adalah kurang.

Tabel 10 Matrik EFAS strategi pencegahan pencemaran lingkungan di PPNpr tahun 2016

\begin{tabular}{|c|c|c|c|c|c|}
\hline & Pertanyaan faktor-faktor ekstrenal & Bobot & Skor & $\begin{array}{l}\text { Jumlah } \\
\text { responden }\end{array}$ & $\begin{array}{c}\text { Jumlah } \\
\text { Nilai }\end{array}$ \\
\hline \multicolumn{6}{|c|}{ Peluang (Opportunity) } \\
\hline & $\begin{array}{l}\text { Adanya peraturan yang dibuat oleh } \\
\text { pemerintah pusat dalam mendukung } \\
\text { pelaksanaan pencegahan pencemaran } \\
\text { lingkungan }\end{array}$ & 2.3 & 2 & 15 & 70.0 \\
\hline (1) & $\begin{array}{l}\text { Adanya pengarahan dari hierarkiatas } \\
\text { pengelola pelabuhan perikanan, yaitu } \\
\text { Direktorat PP DJPT KKP, dalam } \\
\text { pelaksanaan pencegahan pencemaran } \\
\text { lingkungan di PPNPr }\end{array}$ & 1.7 & 2 & 16 & 53.3 \\
\hline 3. & $\begin{array}{l}\text { Adanya audit eksternal dari Direktorat } \\
\text { PP DJPT KKP }\end{array}$ & 1.0 & 2 & 16 & 32.0 \\
\hline \multirow[t]{3}{*}{4.} & $\begin{array}{l}\text { Pemberian reward bagi pihak pelabuhan } \\
\text { yang melaksanakan pencegahan } \\
\text { pencemaran lingkungan di PPNPr }\end{array}$ & 1.0 & 2 & 15 & 30.0 \\
\hline & Jumlah Nilai & 6.0 & & & 185.3 \\
\hline & \multicolumn{5}{|l|}{ Ancaman (Threath) } \\
\hline 1. & Sedikitnya partisipasi aktif nelayan & 2.0 & 1 & 20 & 40.0 \\
\hline 2. & Sedikitnya partisipasi aktif pedagang ikan & 2.0 & 1 & 19 & 38.0 \\
\hline 3. & Sedikitnya partisipasi aktif pengolah ikan & 2.0 & 1 & 18 & 36.0 \\
\hline 4. & $\begin{array}{l}\text { Sedikitnya partisipasi aktif pihak } \\
\text { perusahaan }\end{array}$ & 2.0 & 1 & 18 & 40.0 \\
\hline 5. & $\begin{array}{l}\text { Sedikitnya partisipasi aktif pihak } \\
\text { pengelola TPI }\end{array}$ & 2.0 & 1 & 20 & 38.0 \\
\hline
\end{tabular}




\begin{tabular}{llcccc}
\hline 6. $\begin{array}{l}\text { Sedikitnya partisipasi aktif pedagang ikan } \\
\text { keliling } \\
\text { 7. }\end{array}$ & 2.0 & 1 & 19 & 36.0 \\
& $\begin{array}{l}\text { Sedikitnya partisipasi aktif pedagang } \\
\text { makanan }\end{array}$ & 2.0 & 1 & 18 & 36.0 \\
\hline 8. & $\begin{array}{l}\text { Tidak ada partisipasi aktif pengunjung } \\
\text { pelabuhan }\end{array}$ & 2.0 & 1 & 18 & 40.0 \\
9. $\begin{array}{l}\text { Keberadaan Sungai Cipalabuhanratu } \\
\text { berpengaruh terhadap kondisi } \\
\text { lingkungan PPNPr }\end{array}$ & 2.0 & 1 & 20 & 40.0 \\
\hline \multicolumn{1}{c}{ Jumlah Nilai (JN) } & 18.0 & & 344.0 \\
\hline
\end{tabular}

Sumber : PPN Palabuhanratu 2016 (Data diolah kembali)

Hasil perhitungan faktor peluang pencegahan pencemaran di PPNPr yang terlihat pada Tabel 10 memberikan nilai sebesar 185.3 yang termasuk dalam nilai selang pengambilan keputusan faktor peluang $40 \%<\mathrm{JN}<55 \%(124.8<\mathrm{JN}>171.6)$ yang berarti dari sisi faktor peluang adalah cukup. Pada faktor ancaman menghasilkan nilai sebesar 344.0 yang termasuk dalam nilai pengambilan keputusan faktor ancaman $70 \%<=\mathrm{JN}<85 \%(327.6<\mathrm{JN}<397.8)$ yang berarti sisi faktor ancaman adalah baik.

Hasil nilai masing-masing faktor internal dan eksternal berdasar-kan jumlah nilai (JN) responden pada penelitian (Tabel 11) dibandingkan jumlah nilai maksimal (JN Max) disajikan pada (Tabel 12).

Tabel 11 Jumlah nilai (JN) untuk 4 faktor internal dan eksternal serta jumlahnya dari pencegahan pencemaran lingkungan di PPNPr

\begin{tabular}{|c|c|c|c|c|c|}
\hline \multirow[t]{2}{*}{ Item } & \multicolumn{2}{|c|}{ Faktor Internal } & \multicolumn{2}{|c|}{ Faktor Eksternal } & \multirow[t]{2}{*}{ Jumlah JNMax } \\
\hline & 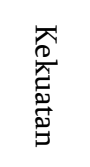 & 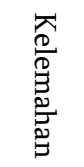 & 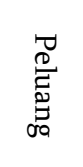 & 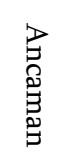 & \\
\hline JN setiap variabel & 433.3 & 290.6 & 185.3 & 344 & \\
\hline $\begin{array}{l}\text { JN variabel internal dan } \\
\text { eksternal }\end{array}$ & \multicolumn{2}{|c|}{142.7} & \multicolumn{2}{|c|}{-158.7} & \\
\hline $\begin{array}{l}\text { JN keseluruhan variabel internal } \\
\text { dan eksternal }\end{array}$ & \multicolumn{4}{|c|}{-16} & 1253.2 \\
\hline
\end{tabular}

Tabel 12 Jumlah nilai maksimal (JNMax) untuk 4 faktor internal dan eksternal serta jumlahnya dari pencegahan pencemaran lingkungan di PPNPr

\begin{tabular}{|c|c|c|c|c|c|}
\hline Item & \multicolumn{2}{|c|}{ Faktor Internal } & \multicolumn{2}{|c|}{ Faktor Eksternal } & Jumlah JNMax \\
\hline & 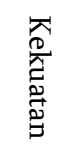 & 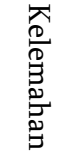 & 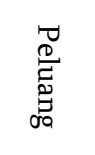 & 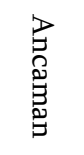 & \\
\hline JNMax setiap variabel & 433.3 & 582.4 & 312.0 & 468.0 & \\
\hline $\begin{array}{c}\text { JNMax variabel internal dan } \\
\text { eksternal }\end{array}$ & \multicolumn{2}{|c|}{-149.1} & \multicolumn{2}{|c|}{-156.0} & \\
\hline $\begin{array}{l}\text { JN Max keseluruhan variabel } \\
\text { internal dan eksternal }\end{array}$ & \multicolumn{4}{|c|}{-305.1} & 1795.7 \\
\hline
\end{tabular}


Berdasarkan tabel diatas diperoleh hasil JN internal sebesar 142.7 dibanding dengan JNMax internal sebesar -149.1 diperoleh hasil selang keputusan $\mathrm{JN}<40 \%(\mathrm{JN}<-59.6)$ yang berarti menurut responden dari sisi faktor internal pencegahan pencemaran di PPNPr adalah sangat kurang.

Jumlah Nilai variabel eksternal diperoleh nilai sebesar -158.7 dibanding dengan JNMax eksternal dengan nilai sebesar -156.0 diperoleh hasil bahwa selang keputusan $\mathrm{JN}>85 \%$ (JN $>-132.6$ ) yang berarti menurut responden dari sisi faktor eksternal pencegahan pencemaran di PPNPr sangat baik. Jumlah nilai keseluruhan 4 faktor internal dan eksternal diperoleh nilai sebesar 1253.2 dibandingkan JNMax keseluruhan variabel internal dan eksternal dengan nilai sebesar 1795.7 diperoleh hasil selang pengambilan keputusan $55 \%<\mathrm{JN}>70 \%(987.6<\mathrm{JN}>1257.0)$ yang berarti menurut responden dari sisi 4 faktor internal dan eksternal pencegahan pencemaran di PPNPr adalah cukup. Penilaian cukup sesuai dengan masih sedikitnya keberadaan fasilitas pencegahan pencemaran lingkungan di PPNPr. Fasilitas yang ada berupa ketersediaan tempat sampah, penampung sampah dan pelumas bekas yang belum optimal. Suherman et al. (2006) menyatakan bahwa tidak adanya fasilitas yang dibutuhkan dan fasilitas yang sudah tidak memenuhi kapasitas dapat menghambat kegiatan operasional suatu pelabuhan perikanan termasuk pada aktivitas pencegahan pencemaran lingkungan pelabuhan. Pelabuhan Perikanan Nusantara Palabuhanratu seharusnya sudah tersedia fasilitas pencegahan pencemaran lingkungan yang memadai.

Penentuan alternatif strategi pencegahan pencemaran lingkungan di PPNPr dihitung berdasarkan faktor-faktor komponen SWOT yang dianalisis menggunakan matrik SWOT (Tabel 13).

Tabel 13 Matrik SWOT strategi pencegahan pencemaran lingkungan di PPNPr tahun 2016

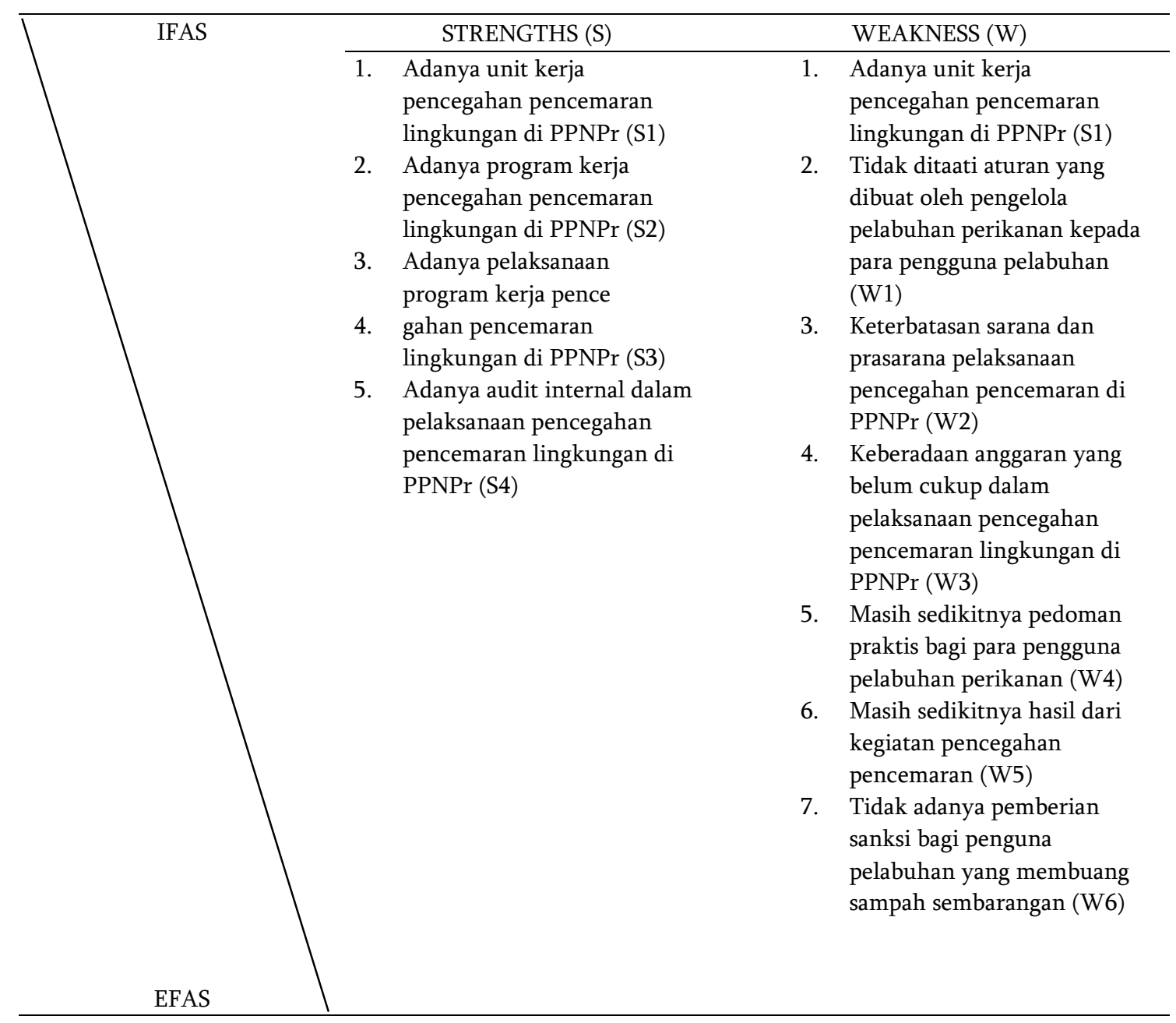




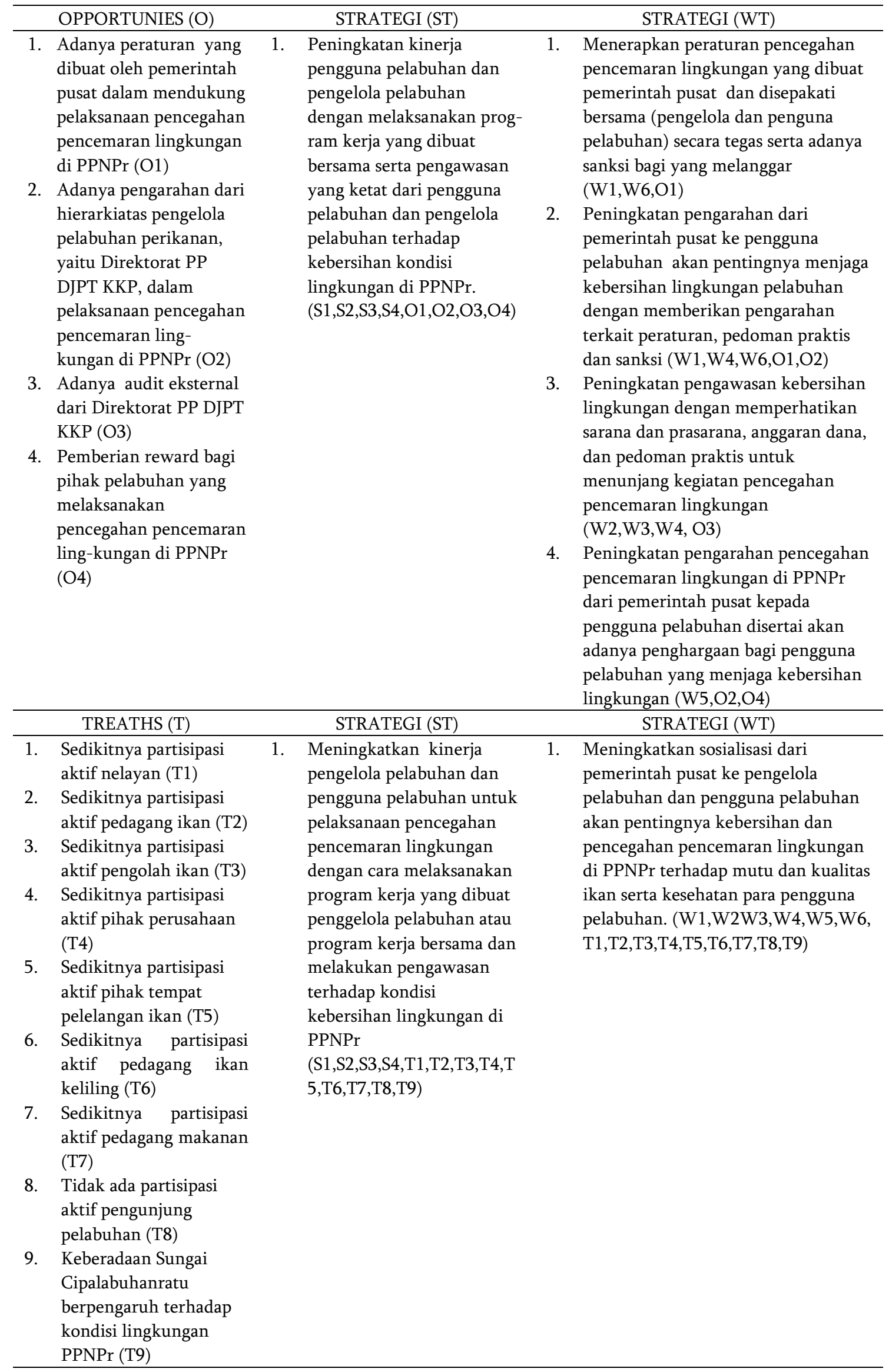


Hasil analisis yang didapatkan yaitu 7 alternatif strategi yaitu baik dari segi kekuatan (Strength), kelemahan (Weakness), peluang (Opportunities) dan ancaman (Threat). Kombinasi strategi StrengthOpportunities (SO) menghasilkan alternatif strategi untuk meningkatan kinerja pengguna pelabuhan beserta pengelola pelabuhan dengan melaksanakan program kerja yang dibuat bersama serta pengawasan yang ketat dari pengguna pelabuhan dan pengelola pelabuhan terhadap kebersihan kondisi lingkungan di PPNPr (S1,S2,S3,S4,O1,O2,O3,O4). Suherman (2011) menyatakan bahwa untuk mengembangkan pelabuhan perikanan berwawasan lingkungan maka harus meningkat-kan sumberdaya manusia dan masyarakat perikanan di sekitar pelabuhan tersebut.

Kombinasi Weakness-Opportunities (WO) menghasilkan alternatif strategi yaitu; 1.) Menerapkan peraturan pencegahan pencemaran lingkungan yang dibuat pemerintah pusat dan disepakati bersama (pengelola dan penguna pelabuhan) secara tegas serta adanya sanksi bagi yang melanggar (W1,W6,O1). 2.) Peningkatan pengarahan dari pemerintah pusat ke pengguna pelabuhan akan pentingnya menjaga kebersihan lingkungan pelabuhan dengan memberikan pengarahan terkait peraturan, pedoman praktis dan sanksi (W1,W4,W6,O1,O2). 3.) Peningkatan pengawasan kebersihan lingkungan dengan memperhatikan sarana dan prasarana, anggaran dana, dan pedoman praktis untuk menunjang kegiatan pencegahan pencemaran lingkungan di PPNPr (W2,W3,W4,O3). 4.) Peningkatan pengarahan pencegahan pencemaran lingkungan di PPNPr dari pemerintah pusat kepada pengguna pelabuhan disertai akan adanya penghargaan bagi pengguna pelabuhan yang menjaga kebersihan lingkungan pelabuhan perikanan (W5, O2,O4).

Kombinasi Strength-Threat (ST) menghasilkan alternatif strategi yaitu meningkatkan kinerja dan pengelola pelabuhan dan pengguna pelabuhan untuk pelaksanaan pencegahan pencemaran lingkungan dengan cara melaksanakan program kerja yang dibuat pengelola pelabuhan atau program kerja bersama dan melakukan pengawasan terhadap kondisi kebersihan lingkungan di PPNPr (S1,S2,S3,S4,T1,T2,T3,T4,T5,T6,T7,T8,T9).

Kombinasi Weakness-Threat (WT) menghasilkan alternatif strategi yaitu meningkatkan sosialisasi dari pemerintah pusat ke pengelola pelabuhan dan pengguna pelabuhan akan pentingnya kebersihan dan pencegahan pencemaran lingkungan di PPNPr terhadap mutu dan kualitas ikan serta kesehatan para pengguna pelabuhan. (W1,W2,W3,W4,W5,W6, T1,T2,T3,T4,T5,T6,T7,T8,T9). Hal ini seperti yang telah dilakukan di Pelabuhan Perikanan Samudera Bitung (PPSB) bahwa Badan Lingkungan Hidup melakukan kegiatan sosialisasi dan pembinaan terhadap pelaku usaha yang ada di dalam kawasan PPSB tentang pengelolaan lingkungan pelabuhan Zhebblon et al. (2016).

\section{KESIMPULAN}

Pelaksanaan pencegahan pencemaran lingkungan di PPNPr telah melakukan kegiatan kebersihan, keamanan dan ketertiban (K3) yang belum optimal (belum dilengkapi peraturan, fasilitas, anggaran, pedoman praktis, sanksi dan sosialisasi) Strategi yang perlu dilakukan untuk pelaksanaan pencegahan pencemaran pelabuhan perikanan di PPNPr yaitu meningkatkan kinerja pengguna pelabuhan dengan melaksana-kan program kerja bersama, penerapan peraturan dengan sanksi yang tegas, dan pengawasan ketat terhadap lingkungan pelabuhan yang berpotensi terjadinya pencemaran lingkungan serta meningkatkan sosialisasi kepada penguna pelabuhan untuk menjaga kebersihan lingkungan pelabuhan.

\section{SARAN}

Perlu dilakukan pelaksanaan peraturan disertai pengawasan, penambahan pedoman praktis, fasilitas, anggaran, dan sanksi terhadap pelanggaran pencemaran serta sosialisasi pencegahan pencemaran lingkungan kepada para pengguna pelabuhan di PPNPr. 


\section{DAFTAR PUSTAKA}

Chen CL, Liu TK. 2013. Fill the gap: developing management strategi to control garbage pollution from fishing vessels. ELSEVIER Marine Pollution Bulletin. (40):34-40.

Culin J, Bielic T. 2016. Plastic pollution from ships. Pomorski zbornik. (51):57-66.

Jailan S, Mimien HIAM, Facthur R, Istamar S. 2016. Sistem pengelolaan dan upaya penanggulangan sampah di Kelurahan Dufa-Dufa Kota Ternate. Jurnal BioeduKasi. 4(2):478-487.

Lubis. E. 2012. Pelabuhan Perikanan. Bogor (ID): IPB Pr.

Pane AB. 2008. Basket hasil tangkapan dan keterkaitannya dengan mutu hasil tangkapan dan sanitasi di TPI PPN Palabuhanratu. Jurnal Ilmu Pertanian Indonesia. 13(3):150-157.

Pane AB. 2016. Metode Skoring Dasar dan Pengembangannya. Bogor (ID: IPB Pr.

[PPN Palabuhanratu] Pelabuhan Perikanan Nusantara Palabuhanratu. 2015. Laporan tahunan PPN Palabuhanratu Tahun 2015. Sukabumi (ID): PPN Palabuhanratu Pr.

Rangkuti. 2016. Analisis SWOT teknik membedah kasus bisnis. Jakarta (ID): PT Gramedia Pustaka Utama pr.

Risnandar. 2013. Pengelolaan lingkungan di pelabuhan perikanan studi kasus di: Pelabuhan Perikanan Nusantara Palabuhanratu [tesis]. Bogor (ID): Institut Pertanian Bogor.

Sari N. 2003. Pengelolaan limbah di dermaga Pelabuhan Perikanan Nusantara Brondong, Kabupaten Lamongan, Jawa Timur. [tesis]. Bandung (ID): Institut Teknologi Bandung.

Sidabur T. 2008. Kondisi Plankton di Teluk Jakarta: Kajian Perubahan Ekologis Teluk Jakarta. Jakarta (ID). LIPI Pr.

Suherman A, Murdiyanto B, Marimin, Sugeng SH. 2006. Analisis pengembangan fasilitas Pelabuhan Perikanan Samudera Cilacap. Jurnal Penelitian Perikanan. 9(1):101-107.

Suherman A. 2011. Formulasi strategi pengembangan pelabuhan perikanan nusantara Pengambengan Jembrana. Jurnal Marine Fisheries. 2(1):87-99.

Suprianto. 2013. Analisis pengelolaan pelabuhan perikanan berwawasan lingkungan di pelabuhan perikanan samudera nizam Zachman Jakarta. Jurnal Ilmu Lingkungan. 7(2):159-179.

[UU RI] Undang-Undang Republik Indonesia. 2009. Undang-Undang Republik Indonesia No 32 Tahun 2009 tentang Perlindungan dan Lingkungan Hidup. Jakarta (ID): Sekretariat Negara.

Wirdah S. 2006. Analisis kebijakan penggelolaan lingkungan Pelabuhan Sunda Kelapa DKI Jakarta. [tesis]. Bogor (ID): Institut Pertanian Bogor.

Zhebblon Ch P, Undap LS, Lasut TM. 2016. Persepsi masyarakat terhadap penerapan ecofishing port di Pelabuhan Perikanan Samudera (PPS) Bitung, Sulawesi Utara. Aquatic Science \& Management. 4(1):21-27. 